\title{
A Tradeoff between Customer Efficiency and Firm Productivity in Service Delivery Systems
}

\author{
Truong Hong Trinh*, Voratas Kachitvichyanukul, Huynh Trung Luong \\ Industrial and Manufacturing Engineering, Asian Institute of Technology, Pathumthani, Thailand
}

(Received: February 13, 2012 / Revised: July 24, 2012 / Accepted: July 31, 2012)

\begin{abstract}
The paper proposes a non-parametric methodology, data envelopment analysis, for measuring efficiency and productivity in service delivery systems with capacity constraints. The methodology provides allocation approaches for studying behaviors of firm and customers in service delivery strategy. The experimental study is carried out to investigate allocation behaviors and conduct an objective tradeoff between efficiency approach and productivity approach. The experimental result indicates that the efficiency approach allocates resource via maximizing customer efficiency rather than firm productivity as in the productivity approach. Moreover, the experiment reveals that there exists an objective tradeoff between the efficiency approach and the productivity approach. These findings provide strategic options for allocation policy in service delivery systems.
\end{abstract}

Keywords: DEA Method, Customer Efficiency, Firm Productivity, Malmquist TFP Index, Service Delivery System

* Corresponding Author, E-mail: Trinh.Hong.Truong@ait.ac.th

\section{INTRODUCTION}

Consumer behavior theory has recognized customers' role in the production and delivery of a service. Chase (1978) recognized the interaction between the customer and the firm, whereas Globerson and Maggard (1991) discussed the importance of integrating the production role of customers into the design of service delivery systems. Sampson and Froehle (2006) stated the presence of significant customer inputs in service processes. Since the customer is regarded as the co-producer (Parks et al., 1981; Wikstrom, 1996; Ojasalo, 2003), customer efficiency has also influence on firm productivity in service delivery systems.

The earlier researchers have proposed non-parametric frontier techniques for measuring efficiency and productivity of decision marking units (DMUs). Data envelopment analysis (DEA) was initiated in 1978 when Charnes, Cooper and Rhodes (CCR) demonstrated how to change a fractional linear measure of efficiency into a linear programming format. Based on the original CCR model, various theoretical extensions have been devel- oped. Banker et al. (1984) extended the application of DEA so that it could be used in situations where the operations are conducted in regions of increasing, constant or decreasing returns to scale. Fare et al. (1992) combined the idea of measuring efficiency by Farrell (1957) with that of measuring productivity by Caves et al. (1982) to develop a Malmquist index of productivity change where the production technology exhibits constant returns to scale. Grifell-Tatje and Lovell (1999) and Balk (2001) extended the formulation of Malmquist total factor productivity (TFP) index for situations where the production technology exhibits variable returns to scale. Many recent researchers have used the non-parametric methodology to measure efficiency and productivity in service delivery systems. Most previous studies measured the Malmquist TFP index with historical production set to evaluate productivity change in hospitals, universities and banks. However, there are still no studies that discuss the interrelationship between firm productivity and customer efficiency.

The concept of customer efficiency was first introduced by Xue and Harker (2002), and the DEA method 
is used to measure customer efficiency in E-shopping. In another research, Xue et al. (2007) investigated relationships among customer characteristics (especially, co-production efficiency), channel utilization, and firm performance in retail banking. Camanho and Dyson (2006) used DEA and Malmquist indices to develop measures for comparing groups of DMUs. The measure clusters the bank branches in different groups according to their managerial strategies and environmental conditions. Felthoven et al. (2009) investigated the presence of heterogeneous production, and measured heterogeneous capacity and capacity utilization. The measure defines capacity as the maximal feasible output that can be produced with the given level of technological, environmental and economic conditions. The contribution of the previous studies allows extending DEA method with capacity constraints to apply the Malmquist productivity index as a planning tool in service delivery strategy.

For that reason, this paper develops output-oriented CCR models under the efficiency approach and the productivity approach applying the non-parametric methodology. The experimental study on a hypothetical service system is carried out to assess allocation behaviors of firm and customers in service delivery strategy. In addition, the experiment uses the multi-objective particle swarm optimization (MOPSO) algorithm from Objective Library for Evolutionary Techniques (ET-Lib; Nguyen et al., 2010) to conduct a tradeoff between customer efficiency and firm productivity. The remainder of this paper is organized as follows: the next section focuses on methodology that presents DEA method, customer efficiency and productivity index. Section 3 describes conceptual models under allocation approaches. Section 4 discuses on numerical experiment, and finally conclusions are drawn in Section 5.

\section{METHODOLOGY}

\subsection{DEA Method}

DEA is a mathematical programming based on nonparametric technique that is designed to compare and evaluate the relative efficiency of a number of DMUs. Since DEA method requires no prior assumption on the specification of the best practice frontier, it is a better way to organize and analyze data since it allows efficiency to change over time. The advantage of the DEA model is that it advises how the unit evaluated should mend its behavior to reach efficiency. However, the main disadvantage of DEA method is that the frontier is sensitive to extreme observations and measurement errors.

The DEA model is designed to compare and evaluate the relative efficiency of a number of DMUs. Consider $n$ DMUs to be evaluated, $\operatorname{DMU}_{\mathrm{o}}(o=1 \cdots n)$ consumes amounts $X_{o}=\left\{X_{o j}\right\}$ of inputs $(j=1 \cdots m)$ and produces amounts $Y_{o}=\left\{Y_{o k}\right\}$ of outputs $(k=1 \cdots s)$. Charnes et al. (1978) were first introduced the primal
CCR model that is used for measuring the efficiency $\left(\Theta_{o}\right)$ of a particular $\mathrm{DMU}_{o}$ as follows:

Fractional programming CCR model:

Max

$$
\Theta_{o}=\frac{\sum_{k=1}^{s} Y_{o k} \times \mu_{o k}}{\sum_{j=1}^{m} X_{o j} \times v_{o j}}
$$

Subject to

$$
\begin{aligned}
& \frac{\sum_{k=1}^{s} Y_{i k} \times \mu_{o k}}{\sum_{j=1}^{m} X_{i j} \times v_{o j}} \leq 1, \quad \forall i=1 \cdots n \\
& v_{o j} \geq 0, \quad \forall j=1 \cdots m \\
& \mu_{o k} \geq 0, \quad \forall k=1 \cdots s
\end{aligned}
$$

Linear programming CCR model:

Max $\Theta_{o}=\sum_{k=1}^{s} Y_{o k} \times \mu_{o k}$

Subject to

$$
\begin{aligned}
& \sum_{j=1}^{m} X_{i j} \times v_{o j}=1, \quad \forall i=1 \cdots n \\
& \sum_{k=1}^{s} Y_{i k} \times \mu_{o k}-\sum_{j=1}^{m} X_{i j} \times v_{o j} \leq 0, \quad \forall i=1 \cdots n \\
& v_{o j} \geq 0, \quad \forall j=1 \cdots m \\
& \mu_{o k} \geq 0, \quad \forall k=1 \cdots s
\end{aligned}
$$

The above primal (multiplier) models are so-called input-oriented CCR models. The objective function presents the ratio of weighted sum of multiple outputs to weighted sum of multiple inputs. The constraint states that if the weights of a DMU are used for other DMUs, their efficiencies should not exceed $100 \%$, in which $v_{o i}$ and $\mu_{o k}$ are non-negativity of weights of inputs and outputs, respectively. In addition, the fractional programming model is transformed to the linear programming model for easy solving. The dual (envelopment) model of the linear programming model can be written under input-oriented and output-oriented CCR models as follows:

Input-oriented CCR model:

Min $\Theta_{o}$

Subject to

$$
\begin{aligned}
& \sum_{i=1}^{n} \lambda_{o i} \times Y_{i k} \geq Y_{o k}, \quad \forall k=1 \cdots s \\
& \Theta_{o} \times X_{o j}-\sum_{i=1}^{n} \lambda_{o i} \times X_{i j} \geq 0, \quad \forall j=1 \cdots m \\
& \lambda_{o i} \geq 0, \quad \forall i=1 \cdots n
\end{aligned}
$$

Output-oriented CCR model:

Max $\Theta_{o}$

Subject to

$$
\sum_{i=1}^{n} \lambda_{o i} \times X_{i j} \leq X_{o j}, \quad \forall j=1 \cdots m
$$




$$
\begin{aligned}
& \Theta_{o} \times Y_{o j}-\sum_{i=1}^{n} \lambda_{o i} \times Y_{i k} \leq 0, \quad \forall k=1 \cdots s \\
& \lambda_{o i} \geq 0, \quad \forall i=1 \cdots n
\end{aligned}
$$

Both CCR models above yield the optimal solution $\Theta^{*}$, which is the efficiency score (so-called technical efficiency or CCR-efficiency) for the particular $\mathrm{DMU}_{o}$, and efficiency scores for all of them are obtained by repeating them for each $\mathrm{DMU}_{o}, o=1 \cdots n$. The value of $\Theta$ is always less than or equal to unity (input-oriented CCR), or greater than or equal to unity (output-oriented $\mathrm{CCR}$ ). $\mathrm{DMU}_{o}$ for which $\Theta^{*}<1$ (or $\Theta^{*}>1$ ) are relatively inefficient and those for which $\Theta^{*}=1$ are relatively efficient, having their virtual input-output combination points on the CCR frontier.

\subsection{Efficiency and Productivity}

In essence, efficiency and productivity are measured upon relationships between input and output. According to Haksever et al. (2000), the productivity of a unit (firm or customer) is the ratio of its output to input used to produce that output, while efficiency is the degree of achievement of a predetermined goal, an optimal outcome or the best practice. An efficient firm (or customer) is one who spends fewer inputs to produce the same amount of or more outputs, or uses the same amount of inputs to produce more outputs. As a result, the efficiency depends on the performance of the firm or the customer, the productivity usually uses in comparing performance of units at a given point of time. Meanwhile, productivity index refers to movement in productivity performance of a firm or customer over time.

Malmquist TFP index was first introduced by Caves et al. (1982), and the method used distance functions in defining the TFP index. Consider $n$ DMUs to be evaluated in period $t, \mathrm{DMU}_{o}(o=1 \cdots n)$ consumes amount of $X_{o}^{t}=\left\{X_{o j}^{t}\right\}$ of inputs $(j=1 \cdots m)$, and produces amounts of $Y_{0}^{t}=\left\{Y_{o k}^{t}\right\}$ of outputs $(k=1 \cdots s)$. The set of production possibilities (technology) of $\mathrm{DMU}_{o}$ in period $t$ can be written as:

$$
S^{t}=\left\{\left(X^{t}, Y^{t}\right) \mid X^{t} \text { can produce } Y^{t}\right\}
$$

Fare et al. (1994) followed Shephard (1970) to define the output distance function in period $t$ and $t+1$ as:

$$
\begin{aligned}
& D_{o}^{t}\left(X^{t}, Y^{t}\right)=\inf \left\{\Theta^{1} \mid\left(X^{t}, Y^{t} / \Theta^{1}\right) \in S^{t}\right\} \\
& D_{o}^{t+1}\left(X^{t+1}, Y^{t+1}\right)=\inf \left\{\Theta^{4} \mid\left(X^{t+1}, Y^{t+1} / \Theta^{4}\right) \in S^{t+1}\right\}
\end{aligned}
$$

The subscript $o$ of $D_{o}^{t}$ is used to denote the outputoriented distance function. Note that $D_{o}^{t}\left(X^{t}, Y^{t}\right) \leq 1$ if and only if $\left(X^{t}, Y^{t}\right) \in S^{t}$, and $D_{o}^{t}\left(X^{t}, Y^{t}\right)=1$ if and only if $\left(X^{t}, Y^{t}\right)$ is on the frontier of the technology. To define the Malmquist index, Fare et al. (1994) defined distance function with respect to two different time pe- riods:

$$
\begin{aligned}
& D_{o}^{t}\left(X^{t+1}, Y^{t+1}\right)=\inf \left\{\Theta^{2} \mid\left(X^{t+1}, Y^{t+1} / \Theta^{2}\right) \in S^{t}\right\} \\
& D_{o}^{t+1}\left(X^{t}, Y^{t}\right)=\inf \left\{\Theta^{3} \mid\left(X^{t}, Y^{t} / \Theta^{3}\right) \in S^{t+1}\right\}
\end{aligned}
$$

The distance function (4) measure the minimal proportional change in output required to make $\left(X^{t+1}, Y^{t+1}\right)$ feasible in relation to technology in period $t$. Similarly, the distance function (5) measure the minimal proportional change in output required to make $\left(X^{t}, Y^{t}\right)$ feasible in relation to technology in period $t+1$.

Malmquist TFP index captures two important sources of productivity changes, gains through efficiency change and technical change as follows:

$$
\begin{aligned}
\underbrace{M_{o}\left(X^{t+1}, Y^{t+1}, X^{t}, Y^{t}\right)}_{\text {Productivity change }} & =\underbrace{\frac{D_{o}^{t+1}\left(X^{t+1}, Y^{t+1}\right)}{D_{t}^{t}\left(X^{t}, Y^{t}\right)}}_{\text {Efficiencychange }} \\
& \times \underbrace{\left[\frac{D_{o}^{t}\left(X^{t+1}, Y^{t+1}\right)}{D_{o}^{t+1}\left(X^{t+1}, Y^{t+1}\right)} \times \frac{D_{o}^{t}\left(X^{t}, Y^{t}\right)}{D_{o}^{t+1}\left(X^{t}, Y^{t}\right)}\right]^{\frac{1}{2}}}_{\text {Telminial change }}
\end{aligned}
$$

where the ratio outside the square brackets measures the change in the output-oriented measure of technical efficiency between periods $t$ and $t+1$, and the geometric mean of the two ratios inside the square brackets captures the shift in technology between the two periods $t$ and $t+1$; this could be called technological progress. Thus,

$$
\begin{aligned}
& \text { Efficiency change }=\frac{D_{o}^{t+1}\left(X^{t+1}, Y^{t+1}\right)}{D_{o}^{t}\left(X^{t}, Y^{t}\right)} \\
& \text { Technical change }=\left[\frac{D_{o}^{t}\left(X^{t+1}, Y^{t+1}\right)}{D_{o}^{t+1}\left(X^{t+1}, Y^{t+1}\right)} \times \frac{D_{o}^{t}\left(X^{t}, Y^{t}\right)}{D_{o}^{t+1}\left(X^{t}, Y^{t}\right)}\right]^{\frac{1}{2}}
\end{aligned}
$$

Following Fare et al. (1992), the production set is known for both periods $t$ and $t+1$, and the four distances which make up Eq. (6) can be estimated via programming techniques. These distance functions are estimated from the primal output-oriented CCR models as follows:

The dual (envelopment) model:

$$
\left[D_{o}^{t}\left(X^{t}, Y^{t}\right)\right]^{-1}=\operatorname{Max} \Theta_{o}^{1}
$$

Subject to

$$
\begin{aligned}
& \sum_{i=1}^{n} \lambda_{o i}^{t} \times X_{i j}^{t} \leq X_{o j}^{t}, \quad \forall j=1 \cdots m \\
& \Theta_{o}^{1} \times Y_{o k}^{t} \leq \sum_{i=1}^{n} \lambda_{o i}^{t} \times Y_{i k}^{t}, \quad \forall k=1 \cdots s \\
& \lambda_{o i}^{t} \geq 0, \quad \forall i=1 \cdots n
\end{aligned}
$$


The primal (multiplier) model:

$$
\left[D_{o}^{t}\left(X^{t}, Y^{t}\right)\right]^{-1}=\operatorname{Min}\left(\sum_{j=1}^{m} X_{o j}^{t} \times v_{o j}^{t} / \sum_{k=1}^{s} Y_{o k}^{t} \times \mu_{o k}^{t}\right)
$$

\section{Subject to}

$$
\begin{aligned}
& \sum_{k=1}^{s} Y_{i k}^{t} \times \mu_{o k}^{t}-\sum_{j=1}^{m} X_{i j}^{t} \times v_{o j}^{t} \leq 0, \quad \forall i=1 \cdots n \\
& v_{o j}^{t} \geq 0, \quad \forall j=1 \cdots m \\
& \mu_{o k}^{t} \geq 0, \quad \forall k=1 \cdots s
\end{aligned}
$$

Where, $\lambda_{\mathrm{oi}}^{\mathrm{t}}=\left(\lambda_{\mathrm{ol}}^{\mathrm{t}}, \lambda_{\mathrm{o} 2}^{\mathrm{t}}, \cdots, \lambda_{\mathrm{on}}^{\mathrm{t}}\right)$ is a vector of weights. The primal model is used to estimate distance function of $D_{o}^{t}\left(X^{t}, Y^{t}\right)$. For the mixed-period cases of $D_{o}^{t}\left(X^{t+1}\right.$, $\left.Y^{t+1}\right)$ and $D_{o}^{t+1}\left(X^{t}, Y^{t}\right)$, the distance function of $D_{o}^{t}\left(X^{t+1}\right.$, $\left.Y^{t+1}\right)$ is computed by the following programming models.

$$
\left[D_{o}^{t}\left(X^{t+1}, Y^{t+1}\right)\right]^{-1}=\operatorname{Max} \Theta_{o}^{2}
$$

Subject to

$$
\begin{aligned}
& \sum_{i=1}^{n} \lambda_{o i}^{t} \times X_{i j}^{t} \leq X_{o j}^{t+1}, \quad \forall j=1 \cdots m \\
& \Theta_{o}^{2} \times Y_{o k}^{t+1} \leq \sum_{i=1}^{n} \lambda_{o i}^{t} \times Y_{i k}^{t}, \quad \forall k=1 \cdots s \\
& \lambda_{o i}^{t} \geq 0, \quad \forall i=1 \cdots n \\
& {\left[D_{o}^{t}\left(X^{t+1}, Y^{t+1}\right)\right]^{-1}=\operatorname{Min}\left(\sum_{j=1}^{m} X_{o j}^{t+1} \times v_{o j}^{t} / \sum_{k=1}^{s} Y_{o k}^{t+1} \times \mu_{o k}^{t}\right)}
\end{aligned}
$$

Subject to

$$
\begin{aligned}
& \sum_{k=1}^{s} Y_{i k}^{t} \times \mu_{o k}^{t}-\sum_{j=1}^{m} X_{i j}^{t} \times v_{o j}^{t} \leq 0, \quad \forall i=1 \cdots n \\
& v_{o j}^{t} \geq 0, \quad \forall j=1 \cdots m \\
& \mu_{o k}^{t} \geq 0, \quad \forall k=1 \cdots s
\end{aligned}
$$

Computing $D_{o}^{t+1}\left(X^{t+1}, Y^{t+1}\right)$ and $D_{o}^{t+1}\left(X^{t}, Y^{t}\right)$ are exactly the same as the above primal models, where $t+1$ is substituted by $t$.

\section{CONCEPTUAL MODELS}

The allocation models are developed upon combining the primal CCR model (Charnes et al., 1978) and distance functions in defining the TFP index (Fare et al., 1994), in which the DEA method is extended with capacity constraints to allocate new resources.

As mentioned earlier, changes in productivity involve both efficiency change and technical change. The distinction between technical change and efficiency change can be made by conceiving the customer as operating in an exogenously determined environment, cal- led the technology, which is the set of all feasible combinations of input and output quantities at a given period (Balk, 2001). A customer which allocates resources on the boundary of this set is called technically efficient. Technical change then means that the set of feasible combinations expands or contracts as illustrated in Figure 1 , while efficiency change means that the customer moves closer to or further away from the boundary.

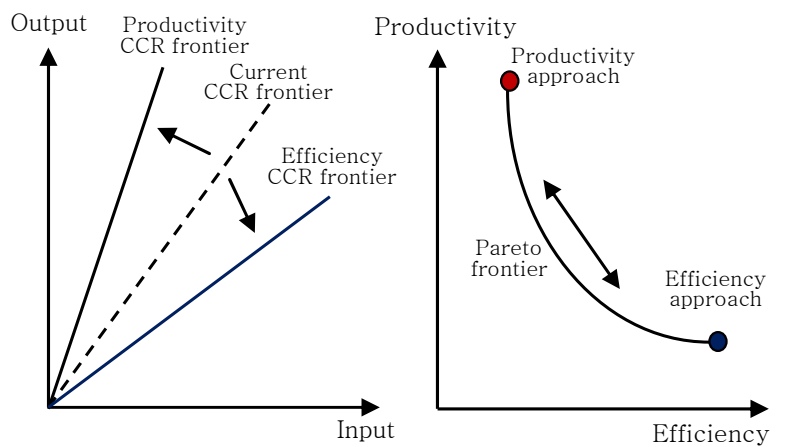

Figure 1. Technical change, efficiency change, and productivity change.

\subsection{Efficiency Allocation Model}

The efficiency approach allocates customer resource (inputs and outputs) within given capacity so as to maximize efficiency change. In order to conduct a new allocation, constraints of capacity (total inputs- $L$, and total outputs- $O$ ) will be added in the primal outputoriented CCR model as follows:

Efficiency allocation model:

$\operatorname{Max} \sum_{o=1}^{n}\left(\frac{\sum_{j=1}^{m} X_{o j}^{t} \times v_{o j}^{t} / \sum_{k=1}^{s} Y_{o k}^{t} \times \mu_{o k}^{t}}{\sum_{j=1}^{m} X_{o j}^{t+1} \times v_{o j}^{t+1} / \sum_{k=1}^{s} Y_{o k}^{t+1} \times \mu_{o k}^{t+1}}\right)$

Subject to

$$
\begin{gathered}
\sum_{o=1}^{n} \sum_{j=1}^{m} X_{o j}^{t+1}=L, \quad\{\text { Capacity of total inputs }\} \\
\sum_{o=1}^{n} \sum_{k=1}^{s} Y_{o k}^{t+1}=O, \quad\{\text { Capacity of total outputs }\} \\
\sum_{k=1}^{s} Y_{i k}^{t} \times \mu_{o k}^{t}-\sum_{j=1}^{m} X_{i j}^{t} \times v_{o j}^{t} \leq 0, \quad \forall o, i=1 \cdots n \\
\sum_{k=1}^{s} Y_{i k}^{t+1} \times \mu_{o k}^{t+1}-\sum_{j=1}^{m} X_{i j}^{t+1} \times v_{o j}^{t+1} \leq 0, \quad \forall o, i=1 \cdots n \\
v_{o j}^{t}, v_{o j}^{t+1} \geq 0, \quad \forall o=1 \cdots n, \quad \forall j=1 \cdots m \\
\mu_{o k}^{t}, \mu_{o k}^{t+1} \geq 0, \quad \forall o=1 \cdots n, \quad \forall k=1 \cdots s \\
X_{L o w e r} \leq X_{o j}^{t+1} \leq X_{U p p e r}, \quad \forall o=1 \cdots n, \quad \forall j=1 \cdots m \\
Y_{L o w e r} \leq Y_{o k}^{t+1} \leq Y_{U p p e r}, \quad \forall o=1 \cdots n, \quad \forall k=1 \cdots s
\end{gathered}
$$


Where, $\sum_{j=1}^{m} X_{o j}^{t} \times v_{o j}^{t} / \sum_{k=1}^{s} Y_{o k}^{t} \times \mu_{o k}^{t}$ and $\sum_{j=1}^{m} X_{o j}^{t+1} \times v_{o j}^{t+1}$ $/ \sum_{k=1}^{s} Y_{o k}^{t+1} \times \mu_{o k}^{t+1}$ are current and new efficiency scores of customer $o(o=1 \cdots n)$. Superscripts $t$ and $t+1$ denote current allocation and new allocation, respectively. Notes that the above allocation model is a non-linear programming model since vectors of weights $\left\{\nu_{o j}^{t+1}\right\}$, $\left\{\mu_{o k}^{t+1}\right\}$, inputs $\left\{X_{o j}^{t+1}\right\}$ and outputs $\left\{Y_{o k}^{t+1}\right\}$ are variables (in range of lower bound and upper bound). The objective function is to maximize efficiency change. This function is formulated from Eq. (7) that represents the ratio of efficiency scores between periods of $t$ and $t+1$.

\subsection{Productivity Allocation Model}

The Malmquist TFP index involves both efficiency change and technical change. The output-oriented CCR model is also employed to measure productivity change under the productivity approach as follows:

Productivity allocation model:

$\operatorname{Max} \sum_{o=1}^{n}\left(\frac{\left(\sum_{j=1}^{m} X_{o j}^{t} \times v_{o j}^{t} / \sum_{k=1}^{s} Y_{o k}^{t} \times \mu_{o k}^{t}\right) \times\left(\sum_{j=1}^{m} X_{o j}^{t} \times v_{o j}^{t+1} / \sum_{k=1}^{s} Y_{o k}^{t} \times \mu_{o k}^{t+1}\right)}{\left(\sum_{j=1}^{m} X_{o j}^{t+1} \times v_{o j}^{t} / \sum_{k=1}^{s} Y_{o k}^{t+1} \times \mu_{o k}^{t}\right) \times\left(\sum_{j=1}^{m} X_{o j}^{t+1} \times v_{o j}^{t+1} / \sum_{k=1}^{s} Y_{o k}^{t+1} \times \mu_{o k}^{t+1}\right)}\right)$

Subject to

$$
\begin{gathered}
\sum_{o=1}^{n} \sum_{j=1}^{m} X_{o j}^{t+1}=L, \quad \text { CCapacity of total inputs } \\
\sum_{o=1}^{n} \sum_{k=1}^{s} Y_{o k}^{t+1}=O, \quad \text { \{Capacity of total outputs } \\
\sum_{k=1}^{s} Y_{i k}^{t} \times \mu_{o k}^{t}-\sum_{j=1}^{m} X_{i j}^{t} \times v_{o j}^{t} \leq 0, \quad \forall o, i=1 \cdots n \\
\sum_{k=1}^{s} Y_{i k}^{t+1} \times \mu_{o k}^{t+1}-\sum_{j=1}^{m} X_{i j}^{t+1} \times v_{o j}^{t+1} \leq 0, \quad \forall o, i=1 \cdots n \\
v_{o j}^{t}, v_{o j}^{t+1} \geq 0, \quad \forall o=1 \cdots n, \forall j=1 \cdots m \\
\mu_{o k}^{t}, \mu_{o k}^{t+1} \geq 0, \quad \forall o=1 \cdots n, \forall k=1 \cdots s \\
X_{L o w e r} \leq X_{o j}^{t+1} \leq X_{\text {Upper }}, \quad \forall o=1 \cdots n, \quad \forall j=1 \cdots m \\
Y_{L o w e r} \leq Y_{o k}^{t+1} \leq Y_{U p p e r}, \quad \forall o=1 \cdots n, \quad \forall k=1 \cdots s
\end{gathered}
$$

Where, the objective function is to maximize the productivity change. This function is formulated from Eq. (6) that involves both the efficiency change and the productivity change.

\subsection{Multi-objective Allocation Model}

The question is whether a tradeoff exists between the efficiency approach and the productivity approach as in Figure 1. The existing tradeoff provides strategic insight on allocation policy in service delivery systems. Thus, the multi-objective allocation model is developed to conduct an objective tradeoff between the efficiency approach and the productivity approach.

Multi-objective allocation model:

$\operatorname{Max} \sum_{o=1}^{n}\left(\frac{\sum_{j=1}^{m} X_{o j}^{t} \times v_{o j}^{t} / \sum_{k=1}^{s} Y_{o k}^{t} \times \mu_{o k}^{t}}{\sum_{j=1}^{m} X_{o j}^{t+1} \times v_{o j}^{t+1} / \sum_{k=1}^{s} Y_{o k}^{t+1} \times \mu_{o k}^{t+1}}\right)$
$\operatorname{Max} \sum_{o=1}^{n}\left(\frac{\left(\sum_{j=1}^{m} X_{o j}^{t} \times v_{o j}^{t} / \sum_{k=1}^{s} Y_{o k}^{t} \times \mu_{o k}^{t}\right) \times\left(\sum_{j=1}^{m} X_{o j}^{t} \times v_{o j}^{t+1} / \sum_{k=1}^{s} Y_{o k}^{t} \times \mu_{o k}^{t+1}\right)}{\left(\sum_{j=1}^{m} X_{o j}^{t+1} \times v_{o j}^{t} / \sum_{k=1}^{s} Y_{o k}^{t+1} \times \mu_{o k}^{t}\right) \times\left(\sum_{j=1}^{m} X_{o j}^{t+1} \times v_{o j}^{t+1} / \sum_{k=1}^{s} Y_{o k}^{t+1} \times \mu_{o k}^{t+1}\right)}\right)$

Subject to

$$
\begin{aligned}
& \sum_{o=1}^{n} \sum_{j=1}^{m} X_{o j}^{t+1}=L, \quad\{\text { Capacity of total inputs } \\
& \sum_{o=1}^{n} \sum_{k=1}^{s} Y_{o k}^{t+1}=O, \quad\{\text { Capacity of total outputs } \\
& \sum_{k=1}^{s} Y_{i k}^{t} \times \mu_{o k}^{t}-\sum_{j=1}^{m} X_{i j}^{t} \times v_{o j}^{t} \leq 0, \quad \forall o, i=1 \cdots n \\
& \sum_{k=1}^{s} Y_{i k}^{t+1} \times \mu_{o k}^{t+1}-\sum_{j=1}^{m} X_{i j}^{t+1} \times v_{o j}^{t+1} \leq 0, \quad \forall o, i=1 \cdots n \\
& v_{o j}^{t}, v_{o j}^{t+1} \geq 0, \quad \forall o=1 \cdots n, \quad \forall j=1 \cdots m \\
& \mu_{o k}^{t}, \mu_{o k}^{t+1} \geq 0, \quad \forall o=1 \cdots n, \forall k=1 \cdots s \\
& X_{L o w e r} \leq X_{o j}^{t+1} \leq X_{U p p e r}, \quad \forall o=1 \cdots n, \quad \forall j=1 \cdots m \\
& Y_{L o w e r} \leq Y_{o k}^{t+1} \leq Y_{U p p e r}, \quad \forall o=1 \cdots n, \quad \forall k=1 \cdots s
\end{aligned}
$$

\section{NUMERICAL EXPERIMENT}

The hypothetical service system under experiment has a single channel $(c=1), 5$ customers (DMUs) with single input and single output with value range of 1 (lower bound) to 9 (upper bound). The data of the hypothetical system is given as in Table 1 .

Table 1. The data of the system with the current allocation

\begin{tabular}{|cccc|}
\hline DMU i & Input $\mathrm{X}^{\mathrm{t}}$ & ${\text { Output } \mathrm{Y}^{\mathrm{t}}}$ & Efficiency score \\
\hline \hline $\mathrm{A}$ & 1 & 1 & 2.00 \\
$\mathrm{~B}$ & 2 & 4 & 1.00 \\
$\mathrm{C}$ & 3 & 6 & 1.00 \\
$\mathrm{D}$ & 4 & 5 & 1.60 \\
$\mathrm{E}$ & 6 & 7 & 1.714 \\
Total & 16 & 23 & \\
\hline
\end{tabular}

The output-oriented CCR model is used to measure scores of customer efficiency. Figure 2 illustrates a graph 
for the current allocation.

The objective of the experiment is to investigate allocation behaviors under the efficiency approach and the productivity approach, and conduct the objective tradeoff between the efficiency approach and the productivity approach. The experiment is designed for two main cases of the same capacity (total input of 16 , and total output of 23) and the capacity change (total input of 18, and total output of 25). The experiment uses outputoriented CRR models to measure the efficiency change and the productivity change.

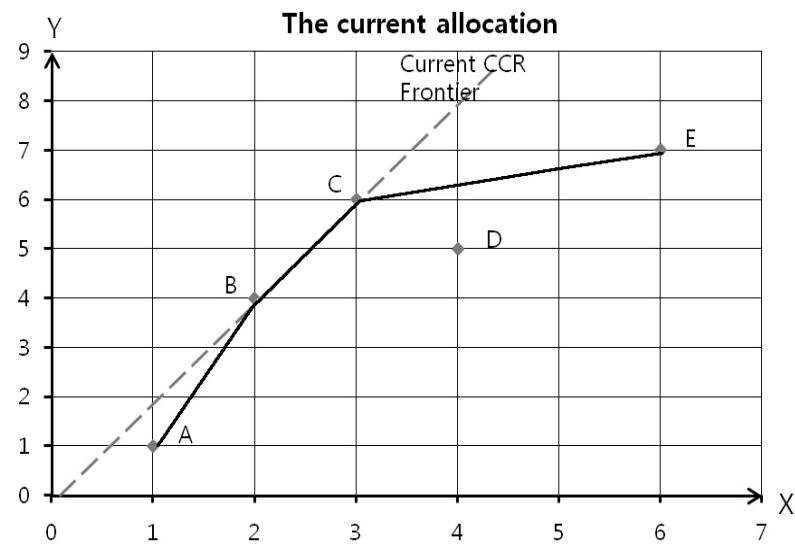

Figure 2. Illustrated graph for the current allocation.

In order to identify objective tradeoffs (Pareto fronts) between the efficiency approach and the productivity approach, the experiment uses MOPSO algorithm from ET-Lib objective library for evolutionary techniques (Nguyen et al., 2010).

Key parameters of MOPSO algorithm used in experiment are as follows:

- Population size (number of particles) is 50 particles.

- Personal/global/local/neighbor acceleration constants $\left(c_{p} / c_{g} / c_{/} / c_{n}\right)$ are $1 / 1 / 1 / 1$.

- Number of iteration is 500 .

- The maximal/minimal inertia weights $\left(w_{\max } / w_{\min }\right)$ are $0.9 / 0.4$

Movement strategy that is used to identify a set of non-dominated solutions (Pareto fronts) is "explore solution space with mixed population of particles" that takes advantages of different search strategies in the algorithm toward a high quality Pareto fronts (Nguyen and Kachitvichyanukul, 2010).

Table 2 presents the current and new allocations under the efficiency approach with the same capacity. The experiment result indicates that most of the customers (DMUs) allocate their resource $(X$ and $Y)$ via improving efficiency score. There are two efficient customers (B and $\mathrm{C}$ ) in the current allocation, but there are four efficient customers in the new allocation (new efficiency score equal to 1 ). It notes that customer B be- comes inefficient in the new allocation due to efficiency score changing from 1 to 1.125 .

Even the new allocation improves almost customer efficiency scores with the sum of efficiency change of 7.20 , but technological progress is reduced as in Figure 3. Slope of CCR frontiers illustrates the technological progress for the system with single input and single output. The technical change from the current allocation to the new allocation is 0.75 .

Table 3 presents the new allocation under the efficiency approach with the capacity change. The results are similar to the resource allocation with the same capacity. Most customer efficiency scores are increased, but technological progress is decreased. Customers B and $\mathrm{C}$ are efficient in the current allocation, but they are inefficient in the new allocation. The technical change of 0.75 may cause inefficiency (but not often) of customers B and C. It means that if there are no conditions in customer behavior (definition of lower bound and upper bound), then customers allocate their resource via improving the efficiency change rather than the technical change.

Table 4 presents the productivity approach for resource allocation with the same capacity. Since the objective function is to maximize productivity change, customer resource is allocated so as to maximize the productivity change if possible. The experiment indicates that the productivity approach improves technical change (4.00) rather than efficiency change (4.70) as in Table 6. In fact, the efficiency score of customers may be decreased in the new resource allocation. Only customers $\mathrm{A}, \mathrm{D}$, and $\mathrm{E}$ are more efficient with efficiency change of $1.75,1.20$, and 1.71 , respectively, the remaining customers are worse in both efficiency score and efficiency change. It notes that customers $\mathrm{B}$ and $\mathrm{C}$ are efficient in the current allocation, but they are inefficient in the new allocation.

Figure 4 shows the productivity allocation approach with the same capacity. The increasing slope of new CCR frontier reveals that the technological progress (technical change) is improved. By observing the current allocation and the new allocation, it seems that allocation of customers B and C are improperly (fall in inefficient region). The efficient region is defined by lower and upper bounds where new allocation of $\mathrm{X}$ and $\mathrm{Y}$ are non-dominant or better than the current allocation.

Table 5 presents the new allocation with total input of 18 and total output of 25 . The productivity change is 20.86 estimated by product of efficiency change (4.63) and technical change (4.50). Table 6 gives the comparison of two approaches in terms of efficiency change, technical change and productivity change. The efficiency approach allocates resource via maximizing efficiency change (7.20), while productivity approach allocates customer resource on the best way of productivity change (18.82). These changes provide firm about customer behavior as well as policy feedback. Further, it also determines useful boundaries for improving indi- 
Table 2. Efficiency approach for resource allocation with the same capacity

\begin{tabular}{|cccccccc|}
\hline DMU i & Current $\mathrm{X}^{\mathrm{t}}$ & ${\text { Current } \mathrm{Y}^{\mathrm{t}}}$ & New $\mathrm{X}^{\mathrm{t}+1}$ & ${\text { New } \mathrm{Y}^{\mathrm{t}+1}}$ & Current efficiency & New efficiency & Efficiency change \\
\hline \hline A & 1 & 1 & 4 & 6 & 2 & 1 & 2.00 \\
$\mathrm{~B}$ & 2 & 4 & 6 & 8 & 1 & 1.125 & 0.89 \\
$\mathrm{C}$ & 3 & 6 & 2 & 3 & 1 & 1 & 1.00 \\
D & 4 & 5 & 2 & 3 & 1.6 & 1 & 1.60 \\
E & 6 & 7 & 2 & 3 & 1.714 & - & 1.71 \\
Total & 16 & 23 & 16 & 23 & - & - & 7.20 \\
\hline
\end{tabular}

DMU: decision making unit.

Table 3. Efficiency approach for resource allocation with the capacity change

\begin{tabular}{|cccccccc|}
\hline DMU i & Current $\mathrm{X}^{\mathrm{t}}$ & ${\text { Current } \mathrm{Y}^{\mathrm{t}}}$ & New $\mathrm{X}^{\mathrm{t}+1}$ & ${\text { New } \mathrm{Y}^{\mathrm{t}+1}}$ & Current efficiency & New efficiency & Efficiency change \\
\hline \hline A & 1 & 1 & 2 & 3 & 2 & 1 & 2.00 \\
$\mathrm{~B}$ & 2 & 4 & 5 & 7 & 1 & 1.07 & 0.93 \\
$\mathrm{C}$ & 3 & 6 & 7 & 9 & 1 & 1.167 & 0.86 \\
$\mathrm{D}$ & 4 & 5 & 2 & 3 & 1.6 & 1 & 1.60 \\
E & 6 & 7 & 2 & 3 & 1.714 & 1 & 1.71 \\
Total & 16 & 23 & 18 & 25 & - & - & 7.10 \\
\hline
\end{tabular}

DMU: decision making unit.

Table 4. Productivity approach for resource allocation with the same capacity

\begin{tabular}{|cccccccc|}
\hline DMU i & Current $\mathrm{X}^{\mathrm{t}}$ & ${\text { Current } \mathrm{Y}^{\mathrm{t}}}$ & New $\mathrm{X}^{\mathrm{t}+1}$ & New $\mathrm{Y}^{\mathrm{t}+1}$ & Current efficiency & New efficiency & Productivity change \\
\hline \hline A & 1 & 1 & 1 & 7 & 2 & 1.143 & 7.00 \\
B & 2 & 4 & 8 & 1 & 1 & 64 & 0.06 \\
C & 3 & 6 & 5 & 1 & 1 & 40 & 0.10 \\
D & 4 & 5 & 1 & 6 & 1.6 & 1.333 & 4.80 \\
E & 6 & 7 & 1 & 8 & 1.714 & 1 & 6.86 \\
Total & 16 & 23 & 16 & 23 & - & - & 18.82 \\
\hline
\end{tabular}

DMU: decision making unit.

Table 5. Productivity approach for resource allocation with the capacity change

\begin{tabular}{|cccccccc|}
\hline DMU i & Current $\mathrm{X}^{\mathrm{t}}$ & ${\text { Current } \mathrm{Y}^{\mathrm{t}}}$ & New $\mathrm{X}^{\mathrm{t}+1}$ & New $\mathrm{Y}^{\mathrm{t}+1}$ & Current efficiency & New efficiency & Productivity change \\
\hline \hline A & 1 & 1 & 1 & 9 & 2 & 1 & 9.00 \\
B & 2 & 4 & 9 & 1 & 1 & 81 & 0.06 \\
C & 3 & 6 & 6 & 1 & 1 & 54 & 0.08 \\
D & 4 & 5 & 1 & 5 & 1.6 & 1.8 & 4.00 \\
E & 6 & 7 & 1 & 9 & 1.714 & 1 & 7.72 \\
Total & 16 & 23 & 18 & 25 & - & - & 20.86 \\
\hline
\end{tabular}

DMU: decision making unit.

Table 6. Comparison of two approaches in the same capacity $(16,23)$

\begin{tabular}{|ccccccc|}
\hline & \multicolumn{3}{c}{ Efficiency approach } & \multicolumn{2}{c|}{ Productivity approach } \\
\cline { 2 - 7 } DMU i & $\begin{array}{c}\text { Efficiency } \\
\text { change }\end{array}$ & $\begin{array}{c}\text { Technical } \\
\text { change }\end{array}$ & $\begin{array}{c}\text { Productivity } \\
\text { change }\end{array}$ & $\begin{array}{c}\text { Efficiency } \\
\text { change }\end{array}$ & $\begin{array}{c}\text { Technical } \\
\text { change }\end{array}$ & $\begin{array}{c}\text { Productivity } \\
\text { change }\end{array}$ \\
\hline \hline A' & 2.00 & 0.75 & 1.50 & 1.75 & 4.00 & 7.00 \\
B' & 0.89 & 0.75 & 0.67 & 0.02 & 4.00 & 0.06 \\
C' & 1.00 & 0.75 & 0.75 & 0.03 & 4.00 & 0.10 \\
D' & 1.60 & 0.75 & 1.20 & 1.20 & 4.00 & 4.80 \\
E' & 1.71 & 0.75 & 1.29 & 1.71 & 4.00 & 6.86 \\
Total & 7.20 & 0.75 & 5.40 & 4.70 & 4.00 & 18.82 \\
\hline
\end{tabular}

DMI J: decision making unit 
vidual customer efficiency and firm productivity performance as a whole.

Figure 5 illustrates non-dominated feasible solutions that represent the objective tradeoff between the efficiency approach and the productivity approach, in which the efficiency approach and the productivity approach are two extreme solutions. Since there is an existing tradeoff between the efficiency approach and the productivity approach, it provides managerial indicators on allocation policy in service delivery systems.

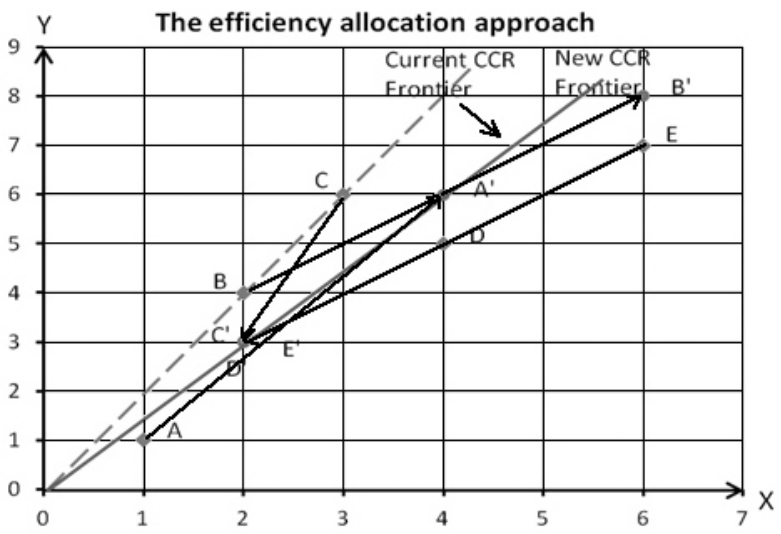

Figure 3. Efficiency approach for the resource allocation.

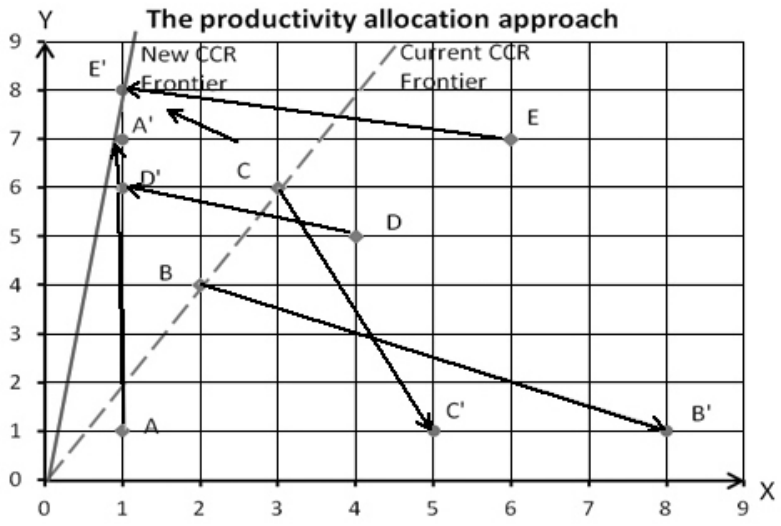

Figure 4. Productivity approach for the resource allocation.

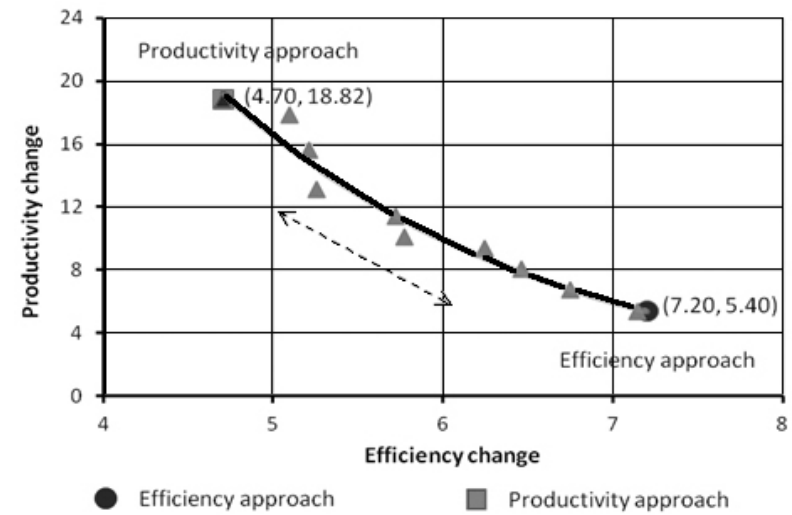

Figure 5. The tradeoff between efficiency approach and productivity approach.

\section{CONCLUSION}

The paper extends the DEA method with capacity constraints to measure efficiency and productivity as a planning tool. The output-oriented CCR models are developed for studying their behaviors in resource allocation under the efficiency approach and the productivity approach. The experimental result indicates that the efficiency approach intends to allocate resource by improving customer efficiency rather than firm productivity as in the productivity approach. Moreover, these allocation approaches are also extreme strategic allocation options, and there exists a tradeoff between customer efficiency and firm productivity. The study result contributes strategic insight on allocation policy in service delivery systems. The paper also gives some suggestions for future researches. First, the paper employs CCR models (constant returns to scale) instead of BCC models (variable returns to scale). Second, the hypothetical service system with single input and single output is proposed for the experimental study. Thus, future research should conduct scale efficiency and mixed effect in allocation models. Finally, it also recommends that variable boundaries should be defined to extend the reality of the allocation problem.

\section{ACKNOWLEDGMENTS}

The authors are grateful to anonymous referees for valuable comments which helped improve the overall contents and presentation of the paper considerably.

\section{REFERENCES}

Balk, B. M. (2001), Scale efficiency and productivity change, Journal of Productivity Analysis, 15(3), 159-183.

Banker, R. D., Charnes, A., and Cooper, W. W. (1984), Some models for estimating technical and scale inefficiencies in data envelopment analysis, Management Science, 30(9), 1078-1092.

Camanho, A. and Dyson, R. (2006), Data envelopment analysis and Malmquist indices for measuring group performance, Journal of Productivity Analysis, 26(1), 35-49.

Caves, D. W., Christensen, L. R., and Diewert, W. E. (1982), The economic theory of index numbers and the measurement of input, output, and productivity, Econometrica, 50(6), 1393-1414.

Charnes, A., Cooper, W. W., and Rhodes, E. (1978), Measuring the efficiency of decision making units, European Journal of Operational Research, 2(6), 429-444.

Chase, R. B. (1978), Where does the customer fit in a service operation? Harvard Business Review, 56(6), 
137-142.

Fare, R., Grosskopf, S., Lindgren, B., and Roos, P. (1992), Productivity changes in Swedish pharamacies 1980-1989: a non-parametric Malmquist approach, Journal of Productivity Analysis, 3(1/2), 85-101.

Fare, R., Grosskopf, S., Norris, M., and Zhang, Z. (1994), Productivity growth, technical progress, and efficiency change in industrialized countries, American Economic Review, 84(1), 66-83.

Farrell, M. J. (1957), The measurement of productive efficiency, Journal of the Royal Statistical Society Series A, 120(3), 253-290.

Felthoven, R. G., Horrace, W. C., and Schnier, K. E. (2009), Estimating heterogeneous capacity and capacity utilization in a multi-species fishery, Journal of Productivity Analysis, 32(3), 173-189.

Globerson, S. and Maggard, M. J. (1991), A conceptual model of self-service, International Journal of Operations and Production Management, 11(4), 33-43.

Grifell-Tatje, E. and Lovell, C. K. (1999), A generalized Malmquist productivity index, TOP: An Official Journal of the Spanish Society of Statistics and Operations Research, 7(1), 81-101.

Haksever, C., Render, B., Russell, R. S., and Murdick, R. G. (2000), Service Management and Operations, 2nd ed., Prentice Hall, Upper Saddle River, NJ.

Nguyen, S., Ai, T. J., and Kachitvichyanukul, V. (2010), Object Library for Evolutionary Techniques ET-Lib: User's Guide, High Performance Computing Group, Asian Institute of Technology, Thailand.
Nguyen, S. and Kachitvichyanukul, V. (2010), Movement strategies for multi-objective particle swarm optimization, International Journal of Applied Metaheuristic Computing, 1(3), 59-79.

Ojasalo, K. (2003), Customers' influence on service productivity, SAM Advanced Management Journal, 68(3), 14-19.

Parks, R. B., Baker, P. C., Kiser, L., Oakerson, R., Ostrom, E., Ostrom, V., Percy, S. L., Vandivort, M. B., Whitaker, G. P., and Wilson, R. (1981), consumers as coproducers of public services: some economic and institutional considerations, Policy Studies Journal, 9(7), 1001-1011.

Sampson, S. E. and Froehle, C. M. (2006), Foundations and implications of a proposed unified services theory, Production and Operations Management, 15(2), 329-343.

Shephard, R. W. (1970), Theory of Cost and Production Functions, Princeton University Press, Princeton, NJ.

Wikstrom, S. (1996), The customer as co-producer, European Journal of Marketing, 30(4), 6-19.

Xue, M. and Harker, P. T. (2002), Customer efficiency: concept and its impact on e-business management, Journal of Service Research, 4(4), 253-267.

Xue, M., Hitt, L. M., and Harker, P. T. (2007), Customer efficiency, channel usage, and firm performance in retail banking, Manufacturing and Service Operations Management, 9(4), 535-558. 